\title{
SOLUNUM KAS FizYOLOJISI VE KAS GÜCÜ ÖLÇÜMÜ
}

\author{
RESPIRATORY MASS PHYSIOLOGY AND \\ MUSCLE POWER MEASUREMENT
}

\author{
Gaye Ulubay \\ Başkent Üniversitesi Tıp Fakültesi, Göğüs Hastalıkları Anabilim Dalı, Ankara, Türkiye \\ e-mail: gayeulubay@yahoo.com
}

DOI: $10.5578 / \mathrm{tcb} .2017 .006$

\begin{abstract}
Özet
Solunum kas gücü, zorlu vital kapasite (FVC), vital kapasite (VC), maksimal inspiratuvar basınç (MIP ya da PImax), maksimal ekspiratuvar basınç (MEP ya da PEmax) ve maksimal sniff nazal inspiratuvar basınç (SNIP) testleri ile invaziv olmayan şekilde ölçülebilir. MIP ve SNIP testler, diyafragma ve diğer inspiratuvar kasların gücünü yansıtırken, MEP karın ve diğer ekspiratuvar kasların gücünü yansıtır. Solunum kas gücü ayrıca Sniff özefageal basınç (Sniff Pe), Sniff trans diyafragmatik basınç (Sniff Pdi) ve gastrik basınç ölçüm yöntemleriyle invaziv olarak da ölçülebilir. MIP, MEP ve SNIP ölçümleri için en sık endikasyonlar, klinik olarak solunum kas güçsüzlüğü şüphesi, solunum kas güçsüzlüğü ile uyumlu solunum fonksiyon testi bulguları (örn. açıklanamayan restriktif patern, düşük vital kapasite gibi) ve solunum kas gücünde iyileşme, kötüleşme, stabil seyir durumlarının değerlendirmesidir. Bu bölümde, solunum kaslarının anatomisi, fizyolojisi ve invaziv, noninvaziv yöntemlerle solunum kaslarının değerlendirilme yöntemleri gözden geçirilecektir.
\end{abstract}

Anahtar kelimeler: Solunum kasları, solunum fonksiyon testleri, kas güçsüzlüğü

\begin{abstract}
Respiratory muscle strength can be assessed noninvasively by measuring the forced vital capacity (FVC), vital capacity (VC), maximal inspiratory pressure (MIP or PImax), the maximal expiratory pressure (MEP or PEmax) and maximal sniff nasal inspiratory pressure (SNIP) tests. The MIP and SNIP reflect the strength of the diaphragm and other inspiratory muscles, while the MEP reflects the strength of the expiratory muscles including abdominal muscles and other expiratory muscles. Respiratory muscle strength can also be assessed invasively by Sniff esophageal pressure (Sniff Pe), Sniff transdiaphragmatic pressure (Sniff Pdi), gastric pressure measurement methods. Common indications for measurement of the MIP, MEP, and SNIP include clinically suspected respiratory muscle weakness, lung function consistent with respiratory muscle weakness (e.g., unexplained restrictive pattern, low vital capacity), and evaluation of whether respiratory muscle weakness has improved, remained stable, or worsened. In this topic, the anatomy, physiology of respiratory muscles, and the methods for the evaluation of muscle strength by invasive and noninvasive methods will be reviewed.
\end{abstract}

Keywords: Respiratory muscles, respiratory function tests, muscle weakness

\section{SOLUNUM KASLARININ ANATOMISI}

Solunum yolları burun ile başlar ve arka arkaya birbirini takip ederek burun boşlukları, farenks, larenks, trakea ve bronşlarla devam eder. Bronşlar akciğer içinde giderek incelerek dallara ayrılır ve sonrasında solunumsal yüzeyi meydana getiren alveolleri oluşturarak sonlanır. Dinlenme durumunda inspirasyon; diyafragma, eksternal interkostal ve skalen kasların kasılmasıyla gerçekleştirilir. Sakin solunumda görev yapan bu kaslar, primer inspirasyon kasları olarak adlandırılır. Primer inspirasyon kaslarının kasılmasıyla toraks genişler ve hacmi artar (1).

\section{Üst Hava Yolları}

Farenks kavitesi üç kısımdan oluşur;

1. Nazofarenks: Burun boşluğu arkasında kalan bölüm olup sadece solunum fonksiyonuna sahiptir ve sürekli açıktır.

2. Orofarenks: Hem solunum hem de sindirim fonksiyonunda rol alır. Arka ve yan duvarları farenksin konstrüktör kasları tarafından oluşturulur.

3. Laringofarenks: Ses oluşumunun yanı sıra ekspirasyon ve inspirasyonda solunum havasının alt hava yollarına iletilmesinden sorumludur. Larenksin iskeletini dokuz adet kıkırdak oluşturur. Kıkırdaklar membran ve bağlar tarafından birbirleriyle bağlanmış olup kasları tarafından fonksiyon yapar. 


\section{Diyafragma}

Yaklaşık olarak $250 \mathrm{~cm}^{2}$ alanında göğüs boşluğu ile karın boşluğunu ayıran kubbe şeklinde çizgili kas grubudur. Yatar pozisyonda apneik solunumda akciğerlere giren havanın yaklaşık 2/3'ünden sorumludur ve en önemli inspirasyon kasıdır. Diyafragma, medulla spinasilisin $C_{3}-C_{5}$ segmentleri seviyesinden kaynaklanan frenik sinirlerin aktivasyonuyla kasılır ve abdomene doğru hareket eder. Normal sakin inspirasyonda diyafragma kasılarak, 1-2 cm abdominal boşluğa doğru hareket ederek toraksın dikey çapında artmaya ve aynı zamanda kaburga kenarlarını yanlara doğru iterek toraksın enine çapında artmaya neden olur. Derin inspirasyonda ise diyafragmanın hareketi aşağıya doğru 7-10 cm'ye ulaşır. Böylece derin solunumda abdominal duvarın kompliyans sınırına ulaşıı ır ve abdominal basınç artar. Frenik sinirlerin paralizisinde kostalar arası kaslarla normal sakin solunum sürdürülebilir, bu hastalarda eforda sorun yaşanabilir.

\section{Eksternal İnterkostal Kaslar}

Interkostal kaslar medulla spinalisin $T_{1}-T_{11}$. segmentlerinden çıkan spinal sinirlerle uyarıır. Eksternal interkostal kasların kasılmasının iki sonucu vardır;

1. Toraksı ikinci ve onuncu kaburgalar hizasında yukarı, dışarı doğru kaldırmak ve toraksın enine çapını artırmak.

2. Kaburgalar arasındaki kasları ve dokuları sertleştirmek ve giderek artan intraplevral basıncın negatifliğine karşı göğüs kafesinde oluşabilecek retraksiyonu önlemek.

\section{Skalen Kaslar}

Normal sakin solunumda kasilır ve primer inspirasyon kası olarak görev yaparlar. Kasıldıklarında ilk iki kaburgayı yukarı doğru kaldırarak göğüs kafesini genişletirler.

Özetle istirahat inspirasyonunda bu kasların birlikte kasılması soluk hacmini oluşturur. Diyafragma tek başına kasılırsa göğüs kafesi kaslarında retraksiyon, göğüs kafesi inspiratuvar kasları tek başlarına kasılırsa, diyafragma toraks içine yukarı doğru çöker.

\section{Zorlu İnspirasyon ve Zorlu İnspirasyon Kasları}

Normal sakin solunumda iş görmezler. Özellikle soluk hacminin artırılması gereken fizyolojik ve patolojik koşullarda görev yaparlar. Sternokleidoimastoid, sternumu yukarı kaldıır, yardımcı solunum kasıdır. Sternohyoid kası, sternothyroid, gibi üst hava yollarını kontrol eden istemli kaslar, serratus anterior, pectoralis major, serratus posterior süperior gibi bazı istemli çalışan toraks kasları da yardımcı solunum kaslarıdır. Boyun ve sırt kasları, göğsü yükseltir, sırtı genişletir ve üst solunum yolu kasları, hava yolu direncini azaltır. Bu şekilde egzersizde, öksürük ve hapşırığın inspiratuvar fazlarında veya kronik obstrüktif akciğer hastalığı (KOAH) ve astım gibi hastalıklarda görev alırlar $(1,2)$.

\section{Ekspirasyon Kasları}

Ekspirasyonun primer kası yoktur. Sakin inspiryum sonunda, diyafragma ve diğer inspiratuvar kasları uyaran sinirlerin aktivitesi azalır ve bu kaslar gevşer. Kas kasılması olmayınca göğüs duvarı aktif olarak yukarı dışarı çekilemez ve göğüs kafesi ağırlığı ve esnekliği nedeniyle başlangıç orijinal boyutuna geri döner, diyafragma ise yukarı doğru hareket eder. Bu nedenle sakin ekspirasyon pasiftir, inspirasyon kaslarının gevşemesiyle oluşur. Ancak ekspirasyonda diyafragma, tamamen gevşemez özellikle horizontal pozisyonda bir miktar tonusu devam eder. Bu nedenle ekspirasyondan inspirasyona geçiş yavaş olur. Ayrıca bu durum özellikle obezlerde konuşmaya katkı sağlar (2).

\section{Zorlu Ekspirasyon ve Kasları}

Ekspirasyon her zaman da pasif değildir. Hava yolu direnci normal olan kişiler, egzersiz, konuşma, şarkı söyleme, öksürük ve hapșırığın ekspiratuvar fazlarında zorlu-aktif ekspirasyon yaparlar. Kronik bronşit, astım veya amfizemi olan hastalarda, hava yolu direnci yüksek olduğu için, sakin ekspirasyon yapamazlar ve zorlu ekspirasyon kaslarını kullanarak aktif-zorlu ekspirasyon yaparlar. Zorlu ekspirasyon kasları, hava akımına karșı oluşan direnci yenmek için kasııır. Zorlu ekspirasyon kasları, rektus abdominis, eksternal ve internal oblik kaslar, transversus abdominis gibi abdominal duvar kasları ve internal interkostal kaslardır. Abdominal kasların kasılması abdominal basıncı artııı ve bu basınç diyafragmayı toraks boşluğuna doğru iter ve alt kaburgaları aşağı çeker. Internal interkostal kasların kasılması ise göğüs kafesini içe çeker. Sonuç olarak torasik hacim mümkün olduğunca fazla azaltilır (1) .

Zorlu ekspiryum sırasında küçülen toraks hacmi ile paralel olarak pariyetal plevrada içe yönde itilir. Plevra basıncı ekspiryum boyunca pozitiftir. Bu itici basınç, alveolleri küçülmeye sevkeder ve alveol içindeki ekspiryum havasını dışarıya doğru iter. Akım volüm halkasında, maksimum ekspirasyonda akımların pik yaptığı noktaya kadar etki eden faktörler zorlu ekspirasyonda kasılan ekspirasyon kaslarının gücü ve intratorasik hava yollarının çapı ile elastik liflerin geri çekim gücüdür. Bu nedenle zorlu ekspirasyonun ilk kısımlarında yer alan bölüm istemli kaslarla da yönetilebildiğinden "efor bağımlı" olarak adlandırııı. Maksimum ekspirasyon eğrisinde ekspiratuvar akımların zirve yaptığı noktadan itibaren akımı belirleyen güçler ise hava yolu çapı ve elastik geri çekim basıncıdır (elastik recoil) ve bu kısımlar efordan bağımsız bölümler olarak adlandırılır. 


\section{SOLUNUM KASLARININ FIZYOLOJISi}

Inspiryum ve ekspiryum sırasında göğüs kafesi ve akciğerler diyaframın aşağı ve yukarı hareketiyle uzar ya da kısalır. Kostaların elevasyon ve depresyonuyla da göğüs kafesi anteroposterior çapı artar ya da azalır. Normal sakin solunum tamamen birinci mekanizmayla ve diyafram hareketi gerçekleşir. İnspiryumda diyaframın kasılmasıyla akciğerlerin alt bölümleri aşağıya doğru çekilir, bu hareket akciğerlerin genişlemesiyle sonuçlanır. Ekspiryumda ise diyafram gevşer, akciğer ve göğüs duvarının elastik geri çekilme gücü ve şiddetli ekspiryumda elastik geri çekilme gücüne ek olarak abdominal yapıların toraksa kompresyon oluşturmasıyla akciğerler küçülür ve ekspiryumla hava dışarı çıkar (1).

Akciğerler inspiryum için ayrıca göğüs kafesinin kaldırılması yoluyla da genişletilir. Göğüs kafesi kaldırıldığında, kostalar ve sternum öne doğru yer değiştirir. Böylece, göğüs duvarı anteroposterior çapı artar. Göğüs kafesini kaldıran tüm kaslar inspirasyon kasları, göğüs kafesini deprese eden kaslar ise ekspirasyon kasları olarak adlandırılır. Göğüs kafesini kaldıran en önemli kas eksternal interkostal kaslardır. Sternumu yukarı kaldıran sternokleidomastoid kası, çok sayıda kostaları kaldıran anterior serratus kasları ve ilk iki kostayı kaldıran skalen kasları diğer inspiryum kaslarıdır.

Ekspiryum sırasında göğüs kafesini aşağı çeken kaslar temel olarak abdominal rektus kası ve internal interkostal kaslardır.

Diyafragma muskülofibröz bir yaprak yapısındadır. Toraks ve abdomeni birbirinden ayıran başlıca inspiryum kasıdır (2). Diyafragma elips şeklindedir ve koronal planda oblik görünümde, önü yukarıda arkası aşağı doğrudur. Diyafragmanın iskelete tutunduğu noktalar; önde ksifoid ve simfizis, lateralde 7-12. kostaların ön uçları ve kıkırdakları, arkada ise birinci lumbar vertebranın transvers proses ve ilk üç lumbar vertebranın korpusu ve simfizisleridir (3). Diyafragmanın musküler fiberleri bir noktada toplanarak diyaframın santral tendonunu oluşturur. Santral tendon ince, kollajen fiberlerinin oluşturduğu kuvvetli bir yapı olup elastik değildir. Diyaframın sinir desteği baskın olarak frenik sinirden (C3-5) kaynaklanır.

\section{DIYAFRAM KONTRAKSIYONU}

Sakin solunum sırasında, diyafram kası kısalır, silenderik kısmın aksiyal uzunluğu azalır ve diyafram domu aşağıya doğru yer değiştirir. Sakin solunumda diyafram şeklindeki en önemli değişiklik, aksiyal planda piston gibi diyafram domunun aşağı yer değiştirmesidir (4). Diyaframda meydana gelen basınç farkı (transdiyafragmatik basınç (Pdi): Pab-Ppl) hava akımından sorumludur. Genel olarak, kas fiberinin başlangıç uzunluğu ne kadar fazla ise, o kadar fazla güç oluşturulur yani daha fazla transdiyafragmatik basınç oluşur.

\section{SOLUNUM KAS GÜCÜ ÖLÇÜM YÖNTEMLERi}

Solunum kas gücü ölçüm yöntemleri inspiratuvar ve ekspiratuvar solunum kaslarının gücünü ölçmek amacıyla kullanılır. En yaygın kullanım alanları; solunum kas güçsüzlüğünün tanısı, şiddetinin belirlenmesi ve takibidir. Klinik olarak solunum kas güçsüzlüğünden şüphe edilen hastalarda ve solunum fonksiyon testleri (SFT)'nde açıklanamayan restriktif patern, düşük vital kapasite buna karşın yükselmiş difüzyon kapasitesi görülen hastalarda solunum kas gücü değerlendirmesi önerilir. Klinik olarak solunum kas güçsüzlüğünden şüphe edilmesi gereken durumlar;

1. Solunum kas zayıflığı açıklanamayan dispne, etkin öksürememe, halsizlik, çabuk yorulma ve bilinen nöromusküler kas hastalığı varlığı,

2. Noninvaziv mekanik ventilasyon ile arter kan gazında oksijen $\left(\mathrm{PaO}_{2}\right)$ ve karbondioksit parsiyel basınçlarında $\left(\mathrm{PaCO}_{2}\right)$ hızla ve belirgin düzelme olduktan sonra nazal oksijene geçildiğinde 1-2 saat içinde belirgin hiperkapni ve asidozun tekrar gelişmesi,

3. Spirometride düşük VC olması ve bunun açıklanamaması durumunda,

4. Yoğun bakım ünitelerinde entübe hastaların altta yatan akut hastalığının düzelmesi sonrasında ventilatörden ayırma denemelerinde (weaning) yaşanabilecek başarııızıılardır (5).

Günümüzde en yaygın kullanılan kas gücü ölçüm yöntemleri aşağıda özetlenmiştir.

\section{A. Solunum Fonksiyon Testleriyle Değerlendirme}

1. FVC ve VC ölçümleri: VC ve FVC ölçümleri ekspiryum ile akciğerlerde bulunan tüm havanın TLC seviyesine kadar atılmasıyla elde edilen ölçümlerdir. Bu ölçümlerden FVC zorlu ekspiryumla yapılmaktadır ve VC normalde zorlu ekspiryumda hava yollarının erken kapanmasına bağlı olarak FVC'den daha yüksektir. Hava yolu obstrüksiyonun şiddeti arttıkça bu fark artar.

VC düşüklüğü, solunum kas gücü yetersizliği olan hastalarda SFT'de en dikkat çeken değişikliktir. Inspiryum ile diyafram güçsüzlüğüne bağlı olarak yeterli hacimde alınamayan soluğun, ekspiryum strasında kullanılan kasların güçsüzlüğünün de katkı sağlamasıyla bu hastalarda VC, FVC normale göre daha düşük saptanır (1). Bu hastalarda akciğerler ve göğüs duvarı kompliyansının düşük olması da VC ve FVC'nin düşük olmasının nedenlerindendir (6-8). Kompliyansın düşük olması geçmişte mikroatelektazilerin varlığı ile açıklanmaya çalışılış ise de günümüzde bu açıklama yeterli bulunmamaktadır (9). 
Klinik kullanımda solunum kas güçsüzlüğü varlığı değerlendirilirken VC ve FVC basit spirometre ile ölçülebildiklerinden bu parametreler MIP ve MEP'e göre daha yaygın olarak kullanılmaktadır. VC ve FVC ölçümlerinin diğer yöntemlere göre daha yaygın olarak kullanılan spirometre ile ölçülebilmesi, daha ekonomik olması, ek manevra gerektirmemesi, tekrarlanabilirliğinin yüksek oranda olması ve beklenen değerlerinin iyi tanımlanmış olması önemli avantajlarıdır. Ancak, FVC ve VC'nin düşüklüğü, tek başına değerlendirildiğinde inspiratuvar kas güçsüzlüğünü göstermede MIP kadar güçlü değildir ve kas güçsüzlüğüne özgün bir SFT bulgusu da değildir $(10,11)$. FVC ya da VC'deki düşüklük obstrüktif ve restriktif akciğer hastalıklarında da görülen bir SFT bulgusudur.

FVC ya da VC'nin oturur pozisyonda ve sırt üstü yatar pozisyonda ölçüldüğünde belirgin farklılık göstermesi solunum kas güçsüzlüğünün tanısında önemli ve MIP'dan daha güvenilir kabul edilen bir bulgudur (12). Ayakta pozisyona göre yatar pozisyonda VC'de \%30 ve daha fazla düşüş olması genellikle ciddi solunum kas güçsüzlüğüne işaret eder $(13,14)$. Bu durum yatar pozisyona geçildiğinde abdominal yapıların gücüne karşı koyamayan ve yatar pozisyonda inspiryumda akciğerlerin dolmasına ve ekspiryumda yeterince boşalmasına yeterli desteği sağlayamayan diyafragma ve ekspiratuvar solunum kaslarının güçsüzlüğü nedeniyle oluşur. Diyafram gücü normalin \%30'u ve altına düştüğünde VC'deki düşüş belirginleşir.
Illeri derecede solunum kas güçsüzlüğünde $V C^{\prime}$ deki düşüş dikkat çekicidir ancak hafif derecede solunum kas güçsüzlüğünü göstermede $V C^{\prime} n i n$ tanı değeri zorlu manevralara göre zayıftır $(8,15)$. Amiyotrofik lateral skleroz ve Duchenne musküler distrofide VC'deki düşüş ile sağkalım arasında önemli ilişki olduğu gösterilmiştir $(16,17)$. Kas güçsüzlüğü tanısı konulan hastalarda takipte FVC'nin monitörizasyon amaçı kullanımı oldukça yararlıdır.

Klinik kullanım için oturur ve yatarken FVC ya da VC ile MIP, MEP ve SNIP testlerin tek değil birlikte kullanımı kas güçsüzlüğü tanısında daha yararıdır (18).

Solunum kas güçsüzlüğünde FVC manevrasında maksimum inspiratuvar ve maksimum ekspiratuvar akımlar elastisite ve kompliyansın düşük olması nedeniyle beklenenden daha düşüktür. Bu nedenle akım volüm halkasında inspiratuvar ve ekspiratuvar kısımda basıklaşma (PEF'de belirgin) ve düşme ile RV'ye ulaşmadan hemen önce ekspiryum halkasında aniden akım düşmesi görülür.

Akım volüm halkasında ekstra torasik üst hava yolu obstrüksiyonlarda görülen değişikliğin tersi olarak $\mathrm{FEV}_{1}$, FIV ${ }_{1}$ 'den daha düşüktür. Bu nedenle oluşan görünüm iki durumun ayırt edilmesinde yol gösterici olabilir (19) (Şekil 1). Üst hava yolunu kontrol eden kasların güçsüzlüğünde, akım volüm halkasında ekspiryum ve/veya inspiryumda testere dişi paterni görülebilir (Şekil 2). Bu durum zorlu inspiryum ve/veya ekspiryumda hava yolunun mekaniklerinin kas güçsüzlüğü nedeniyle korunamamasına bağlıdır. Ancak bu görünüm kas güçsüzlüğüne özgün değildir ve uyku bozukluklarında, ekstrapiramidal patolojilerde ya da üst hava yollarının termal hasarlarında da görülebilir (20).

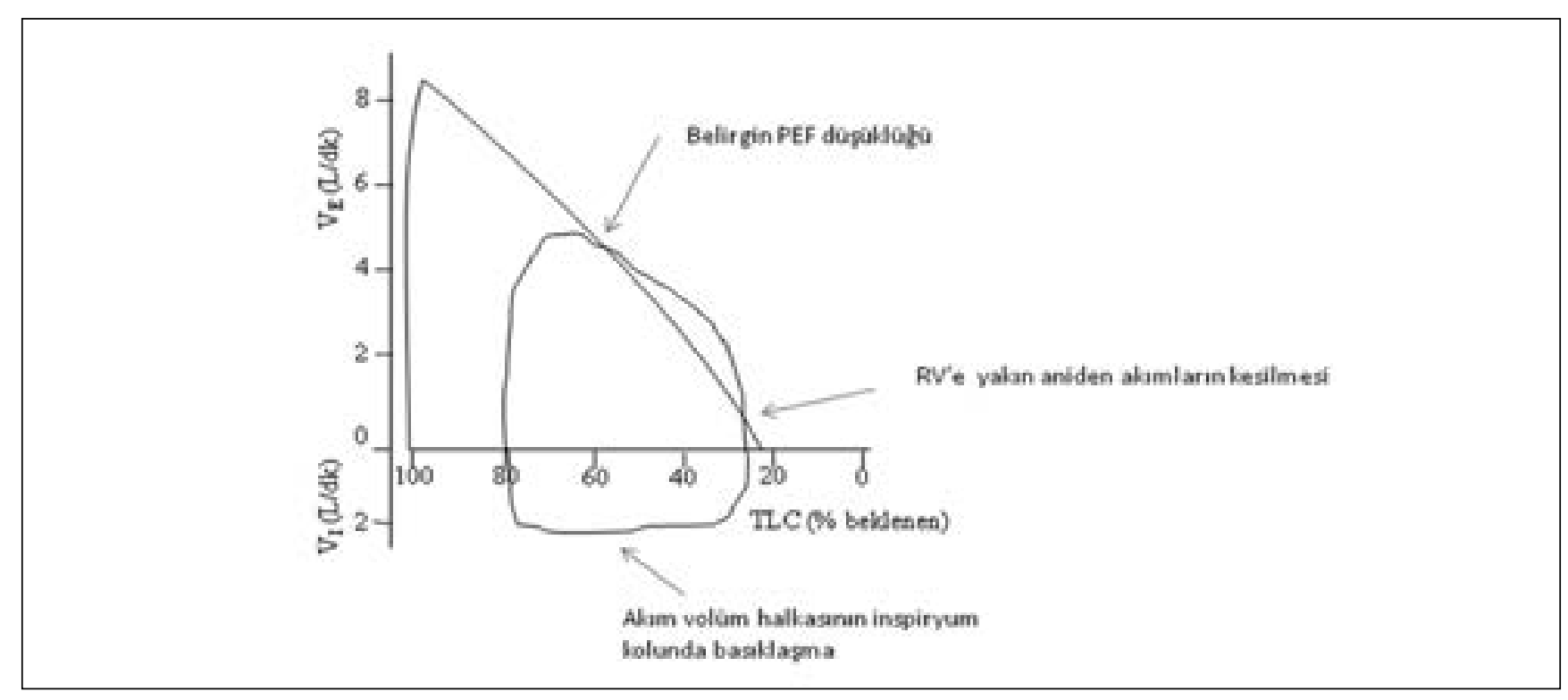

Şekil 1: Solunum kas güçsüzlüğünde akım volüm halkası örneği. 


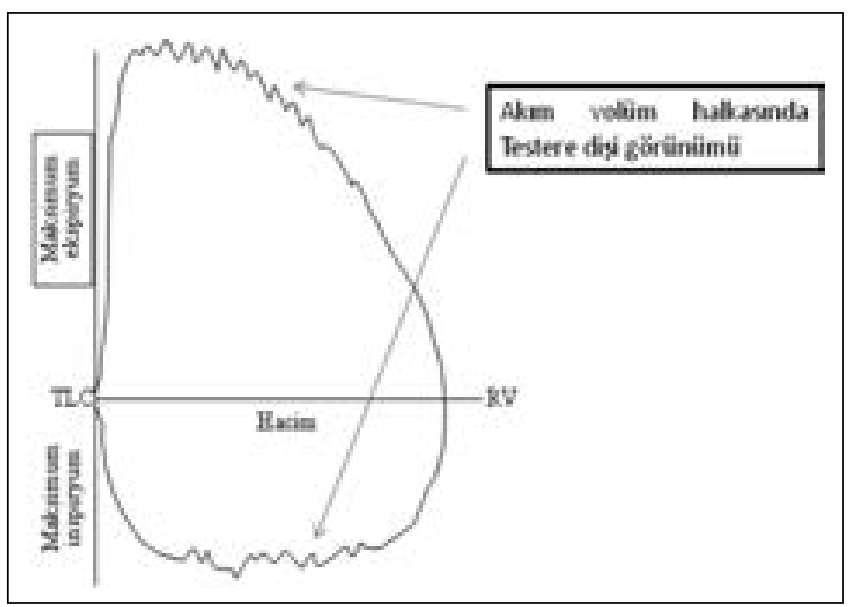

Şekil 2. Solunum kas güçsüzlüğünde akım volüm halkasında "Testere Dişi" görünümü.

2. Total akciğer kapasitesi (TLC), rezidüel volüm (RV), fonksiyonel rezidüel kapasite (FRC): Solunum kas güçsüzlüğü olan hastalarda, inspiryum ve ekspiryum kaslarının güçsüzlüğü bunun sonucunda elastisite ve kompliyansın da düşük olması nedeniyle inspiryum ve ekspiryumda volümler düşüktür. Bu durum TLC'nin de düşük olmasına yol açar. Ekspiryumda akciğerlerdeki havanın tamamen dışarı atılmasını sağlayacak yeterli güç üretilemediği, hava yolları da erken kapandığı için RV artışı da görülebilen bir SFT bulgusudur. RV'deki artış ve TLC'deki düşüş nedeniyle RV/TLC ve FRC/TLC hava yolu obstrüksiyonu olmadığı halde sıklıkla artmışıı (21).

3. Maksimal volunter ventilasyon (MVV): MVV, solunum kas güçsüzlüğü tanısında kullanılabilen bir ölçüm yöntemidir. Bu manevrada, hastanın tıpkı efor yapıyormuş gibi 10 saniye boyunca hızlı hızlı soluk alıp vermesi istenir. Elde edilen değer 6 ile çarpılarak hastanın MVV değeri, yani tahmini 1 dakikalık maksimum dakika ventilasyonu (VE max) değeri hesaplanır $(22,23)$. Test sonuçlarını etkileyen pek çok patolojik durum olması ve testin hasta eforundan fazla etkilenmesi nedeniyle diğer yöntemlere göre daha az tercih edilmektedir.

4. Karbonmonoksit difüzyon kapasitesi $\left(\mathrm{DL}_{\mathrm{co}}\right)$ : $\mathrm{DL}_{\text {co }}$ ölçümü kas güçsüzlüğü olan hastalarda alveolokapiller membranın sağlam olması nedeniyle genellikle normaldir. Ancak, $\mathrm{DL}_{c o}$ manevrası sırasında test gazını kas güçsüzlüğü nedeniyle TLC seviyesine kadar ulaşarak inspire edemeyen hastalarda hafif düşük saptanabilir. $\mathrm{DL}_{\text {co }}$ ölçümü sırasında elde edilen alveoler hacim (VA) bu hastalarda inspiryum hacimlerinin ve kompliyansın düşük olması nedeniyle düşük olabilir. Bu durumda $\mathrm{DL}_{c o}$ NA genellikle normalden daha yüksek olabilir (21).

\section{B. Basınç Ölçüm Yöntemleri}

1. Maksimal inspiratuvar basınç [MIP, PImax ya da zorlu negatif inspirasyonu (NIF)] ve maksimal ekspiratuvar basınç (MEP ya da PEmax) yöntemleri: Bu yöntemlerin her ikisi de rijid, kısa bir tüp sistemi içindeki shutter'a karşı maksimum ekspiryum ve maksimum ekspiryum yapılması sırasında, tüpün içindeki basınç transduseri aracılığıyla tüpün içindeki basıncın ölçülmesi esasına dayanır. Her iki manevra sırasında tip içindeki basınç değişiklikleri basınç ölçere bağlı ölçer bir kateter aracllığıyla bilgisayara taşınır. Elde taşınabilen ya da bilgisayar bağlantılı sistemler aracilığılla ölçüm yapılabilir (23-25) (Resim 1).

MIP: Maksimum efor değerlerinin elde edilebilmesi hastaya testin önceden gösterilerek anlatılması gereklidir. Test sırasında kenarlı bir ağızık, burun mandalı kullanılmalı ve dudak kenarlarından kaçak olmamalıdır. Standart ağızlıklar bu ölçüm sırasında kullanılabilir (Resim 2). Test sırasında hastanın yavaş ekspiryumunu rezidüel volüm seviyesine kadar tamamlaması sonrasında hızlı bir ekspiryum yapması istenir. Bu hızlı ekspiryum sırasında tüp sistemi içindeki shutter kapanır ve kapalı shutter'a karşı hastanın ekspiryum gücü basınç ölçer ile ölçülerek test gerçekleştirilir $(21,26,27)$.

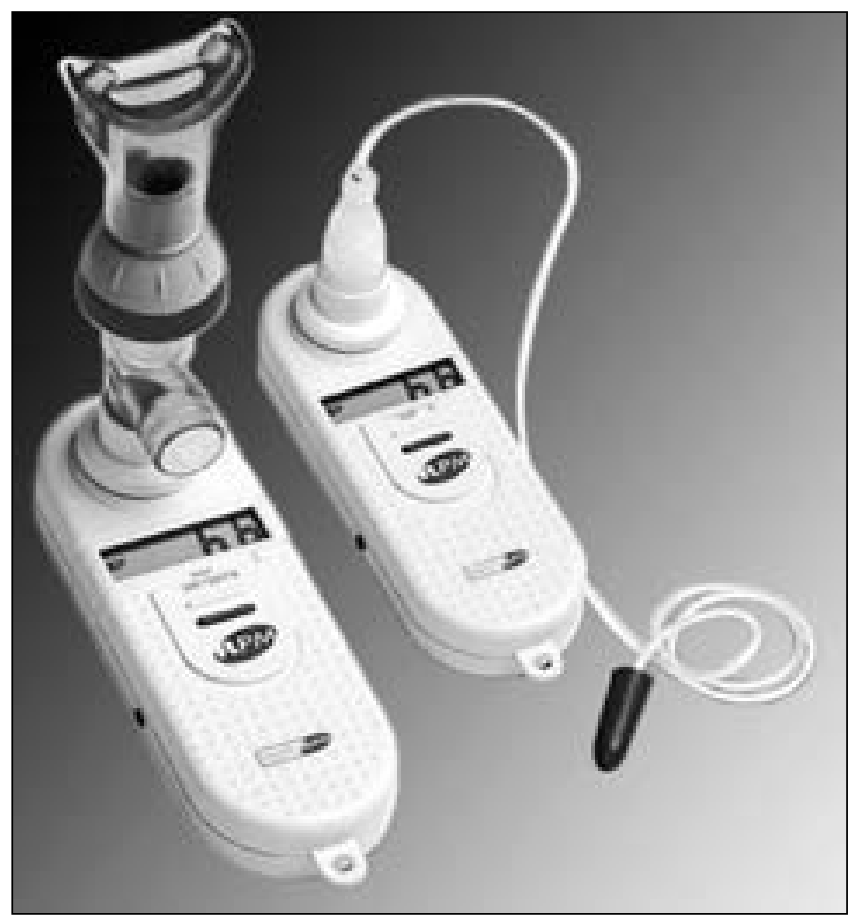

Resim 1. Solunum kas gücü ölçümü için kullanılabilecek portabl cihaz örneği. 


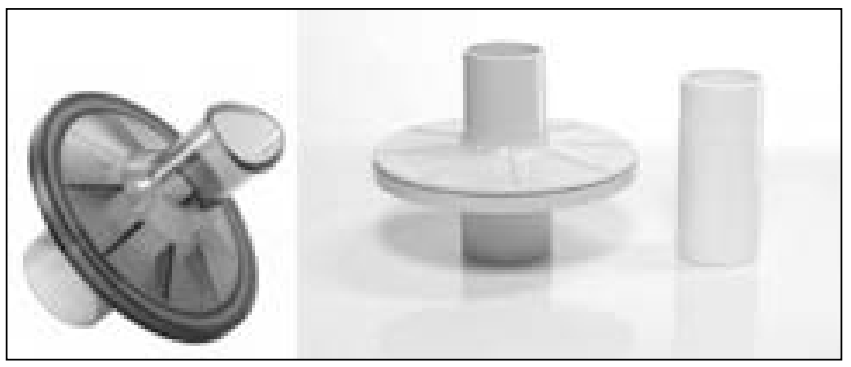

Resim 2. MIP manevrası sırasında kullanılabilecek ağızlıklar.

MEP: Test sırasında kenarlı bir ağızlık, burun mandalı kullanılmalı ve dudak kenarlarından kaçak olmamalıdır. Özellikle MEP ölçümü sırasında klasik ağızlıklar ile kaçak olma riski MEP'e göre daha fazla olduğundan bu tip ağızlıkların kullanılması ile daha başarılı sonuç elde edilir (Resim 3).

Manevra sırasında hastanın bütün gücüyle ve en az 1.5 saniye boyunca balon şişirir gibi ağızlıktan üflemesi istenir. Bu sırada hızlı ekspiryumda yaratılan basınç sensörler aracılığıyla ölçülür ve 1.5-2.0 sn sonra shutter açılır, test sonlanır. Çoklu test yapılacak ise iki test arasında hasta en az 1 dakika dinlendirilir ve en fazla 3-5 test yapılır. Testler arasında $10 \mathrm{cmH}_{2} \mathrm{O}^{\prime}$ dan fazla değişim olmamalıdır. Yapılan en yüksek ölçüm beklenen değer ile birlikte rapor edilir $(23,26,27)$.

MIP ve MEP için spirometri testindeki gibi kesin referans değerleri henüz belirlenememiştir. Farklı yaş gruplarındaki bireylerin referans değerleri, yapılan çalışmalardan elde edilen verilerle oluşturulmaya çalışılmıştır (Tablo 1).

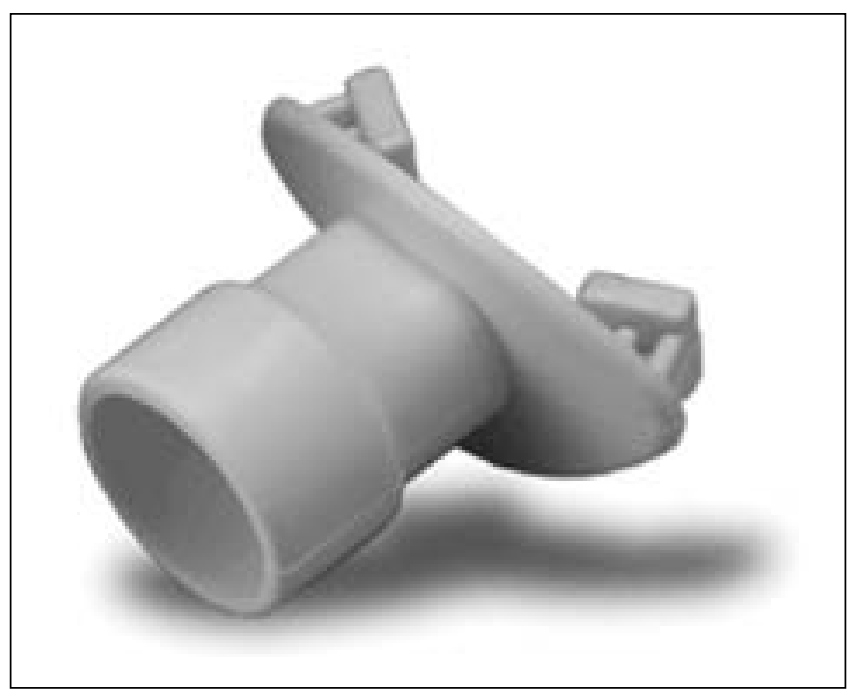

Resim 3. MEP manevrası sırasında kullanılabilecek kenarlı ağılık örneği.
Tablo 1. Çalışmalardan elde edilen referans MIP ve MEP değerleri (28-32).

Çalışma MIP (negatif, $\mathrm{cmH}_{2} \mathrm{O}$ ) MEP (pozitif, $\mathrm{CmH}_{2} \mathrm{O}$ ) popülasyonu

\begin{tabular}{|lll|}
\hline 7-13 yaş (18) & Erkek: 77-114 & Erkek: 99-161 \\
& Kız: 71-108 & Kız: 74-126 \\
13-35 yaş (19) & Erkek: 114-121 & Erkek: 131-161 \\
& Kadın: 65-85 & Kadın: 92-95 \\
18-65 yaş (20) & Erkek: 92-121 & Erkek: 140 \\
& Kadın: 68-79 & Kadın: 95 \\
65-85 yaş (21) & Erkek: $65-90$ & Erkek: $140-190$ \\
& Kadın: $45-60$ & Kadın: $90-130$ \\
\hline & & \\
\hline & &
\end{tabular}

2. Sniff testler: Burun nefes çekme testleri olarak adlandırabileceğimiz bu testler arasında; "Transdiaphragmatic pressure during sniff, esophageal pressure during sniff" ve "nasal sniff pressure (nazal inspiratuvar basınç ölçümü)" genellikle kullanılanlardır. "Transdiaphragmatic pressure during sniff, esophageal pressure during sniff" test yöntemleri "invaziv testler" başlığı altında anlatılacaktır.

Nazal inspiratuvar basınç ölçümü (SNIP): İnspiratuvar kas gücü ölçümünde kullanılan noninvaziv bir yöntemdir $(33,34)$. MIP yöntemine göre daha basit ve hasta uyumu daha fazladır (21). Bu test burun deliği içine yerleştirilen basınç ölçerli bir kateter taşıyan bir tıkaç ve burundan havayı içe çekme sırasında oluşan negatif basıncın inspiratuvar kas gücü değeri olarak $\mathrm{cmH}_{2} \mathrm{O}$ cinsinden ölçülmesi esasına dayanır $(33,34)$. SNIP test ağır hava yolu obstrüksiyonu olan hastalar dışında genellikle Sniff özefagus testine yakın sonuçlar verir (34-36). Çünkü bu hastalarda intratorasik basınç ile nazal basınç arasında fark normalden daha yüksektir. SNIP test maksimal inspiratuvar negatif basınç elde edilinceye kadar 10 teste kadar tekrarlanabilir. Testler arasında yine $20 \mathrm{CmH}_{2} \mathrm{O}^{\prime}$ dan fazla değişim olmaması gereklidir $(21,34)$. Elde edilen maksimum değer rapor edilir.

3. Öksürük testi: Öksürme sırasında birçok inspiratuvar ve ekspiratuvar solunum kasları kullanıı.ır. Bu nedenle öksürük test sonuçları ilgi çekmektedir. $\mathrm{Bu}$ yöntemde balon kateter yerleştirildikten sonra maksimum güç ile öksürtülen hastada özefageal (Pes), nazofarengeal (Pnp) ve ağız içi (Pmo) basınçlar ölçülür (21).

C. İnvaziv Testler: Spirometri, MIP, MEP, SNIP testler ile solunum kas güçsüzlüğü tanısında net karar verilemeyen durumlarda ya da araştırmalar için invaziv testler kullanılabilir. Testlerin özel merkezlerde ve deneyimli kişiler tarafın- 
dan yapılması gereklidir. Bu grup testlerin başlıcaları; "Sniff esophageal pressure (Sniff Pe)", "Sniff transdiaphragmatic pressure (Sniff Pdi)" ve "gastric pressure" dır.

1. Sniff esophageal pressure (Sniff Pe): Inspiratuvar kas gücünü yansıtan bir testtir. Bu test için hastanın uyumu önemlidir.

2. Sniff transdiaphragmatic pressure (Sniff Pdi): Özefageal ve gastrik balon kateterleri aracılığılyla diyafram gücünün direkt ölçülmesi yöntemidir.

3. Gastrik basınç ölçümü: Hızlı ve maksimum bir öksürük sonrasında gastrik balon kateter aracilığıyla gastrik basınç üzerinden ekspiratuvar kas gücünün ölçülmesidir.

Yoğun bakım koşullarında ya da hastanın test uyumunun iyi olmadığı durumlarda diyafragma gücü (Pdi) tek ya da iki taraflı olarak elektriksel ya da manyetik frenik sinir stimülasyonu ile ölçülebilir (36-38). İstemsiz abdominal (ekspiratuvar) kas gücü ölçümü, T10 vertebra seviyesinde yüzeyel manyetik stimülasyonu takiben gastrik basınçların kaydı ile yapılan ölçümdür (39). Frenik gastrik stimülasyon ise, özefageal bir elektrot aracilığılla diyafram EMG'sinin kayıt edilmesi esasına dayanan bir yöntemdir. Frenik sinirin uyarılmasını takiben ileti gecikme süresini ve diyaframda yarattığı aktivite amplitüdünün ölçülmesine olanak verir. İnvaziv yöntemler solunum kas gücü ölçümlerini en doğru şekilde yapmamıza olanak verir. Ancak sınırlı sayıda merkezde yapıldığından invaziv olmayan yöntemler daha yaygın kullanılmaktadır.

\section{Elektrofizyolojik Yöntemler}

1. Elektromiyografi (EMG): Solunum kas gücü değerlendirmesinde EMG, inspiratuvar ya da ekspiratuvar kas lifi üzerine yerleştirilen elektrod, aksiyon potansiyelinin oluşum ve ilerlemesinden sorumlu iyonik akımı kayıt eder. Elektrodlar yüzeyel ya da intramusküler yerleştirilir, monopolar ya da bipolar olabilirler. İntramusküler elektrodlar ilgilenilen kasa yerleştirilirken, yüzeyel elektrodlar mümkün olduğunca ilgilenilen kasa yakın konuma yerleştirilir.

Ekspiryum kaslarını değerlendirmek için çoğunlukla rektus abdominis ya da eksternal oblik kaslar tercih edilirken inpiratuvar kasların değerlendirilmesinde diyafragma kullanılır. Diyafram aktivitesi, kostokondral bileşkede 5, 6 ya da 7. interkostal alana yerleştirilen yüzey elektrodu ile ölçülür (40). Ayrıca diyafram EMG'si, özefagus balon kateter içine yerleştirilen EMG halkaları ile krural diyafram aktivitesi ölçülebilir $(41,42)$.

Tecrübeli kişilerle ve donanımlı merkezlerde yapılması gereklidir.
2. Periferik sinir stimülasyonu: İstemli manevralar ile ölçülen maksimal hava yolu basınçları birçok inspiratuvar ve ekspiratuvar kasların sinerjistik hareketini gösterirken frenik sinir stimülasyonuna cevap olarak ölçülen transdiyafragmatik basınç daha spesifik olarak diyafram değerlendirilmesi sağlar (43). Frenik sinir stimülasyonu esnasında hasta motivasyonuna intiyaç olmaması bir üstünlük teşkil eder ki bu solunum kas fonksiyonu değerlendirmesine temel bir sorunu oluşturur. Ayrıca frenik sinirin fonksiyonel bütünlüğünü, diyafram yorgunluğunu ve yorgunluk türünü (yüksek frekans।ı/düşük frekanslı), diyafram gücünü ve diyaframın güç rezervini belirlemeyi sağlar. Periferik sinir stimülasyonu elektrik ve magnetik stimülatörler vasıtasıyla gerçekleştirilir.

\section{DEĞERLENDIRME}

MIP, MEP ve SNIP test sonuçları, referans değerler ile karşılaştırılarak değerlendirilir. Normal referans değerler için alt üst sınır aralıkları geniştir (28-32). Normal değerler kadınlarda erkeklerden daha düşüktür ve yaş ile her iki cinste de azalır. Hiperinflasyonu ve ileri hava yolu obstrüksiyonu olan hastalarda, diyaframın kısalması ve mekanik olarak kısıtlanması nedeniyle MIP değeri düşüktür (44). Bu hastalarda diyafragmatik kas uzunluğu ile MIP değeri arasında doğru ilişki vardır (Şekil 3).

Ileri derece hava yolu obstrüksiyonu olan hastalarda intratorasik basıncın buruna yansıması yetersizdir bu nedenle bu hastalarda sniff özefageal basınç burun ölçümünde daha negatiftir ve SNIP test yanlış ve daha düşük sonuç verebilir.

MIP, MEP, SNIP test sonuçları değerlendirilirken normalden daha düşük değerlerin kötü efor ya da yanlış manevra yönetimine bağlı olabileceği de düşünülmelidir. MIP ve SNIP testlerin birlikte yapılması bu ihtimali dışlamak için önerilebilir (45). MIP ve MEP'in normal olması solunum kas güçsüz-

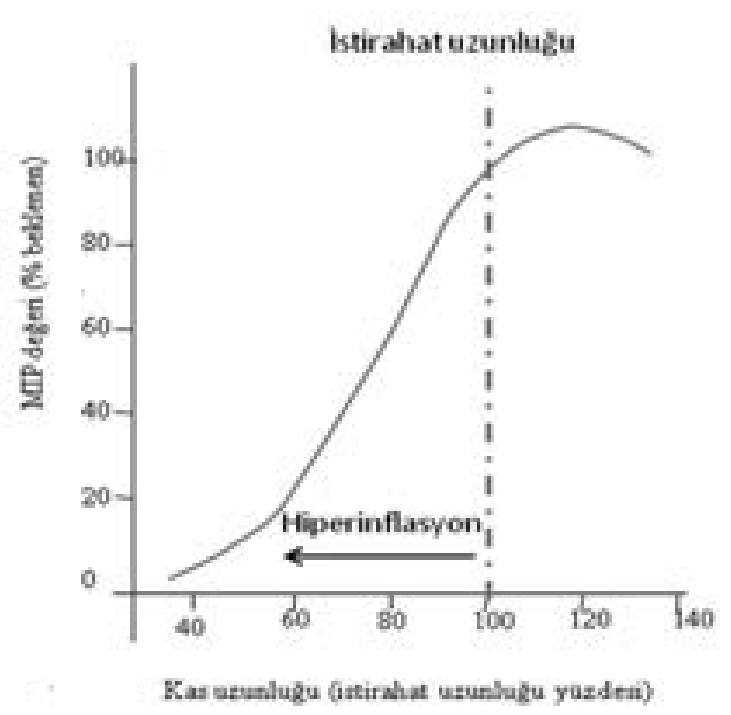

Şekil 3. Kas uzunluğu ve kas gücü arasındaki ilişkinin şematizasyonu. 
lüğünü dışlatırken düşük olması yukarıda belirtilen nedenlere bağıı olarak kas güçsüzlüğü tansını koydurmaz $(46,47)$. $\mathrm{Bu}$ durumda testler tekniğin eforun doğruluğundan emin olmak için tekrarlanır ya da laboratuvar koşulları uygun ise invaziv testlere geçilir.

Solunum kas gücü testlerinin normal popülasyondaki varyasyonları göz önünde bulundurularak özellikle çeşitli hastalıkların kas gücü üzerine etkisini monitörize etmek amacıyla kullanılabileceği belirtilmektedir (48). Sağlıklı kişilerde yapılan çalışmalarda testler arasında $25 \mathrm{CmH}_{2} \mathrm{O}^{\prime}$ dan az değişimler olabildiği gösterilmiştir. Bu çalışmayı destekleyen serilerde MIP -13 $\mathrm{cmH}_{2} \mathrm{O}$ ve MEP için $24 \mathrm{cmH}_{2} \mathrm{O}$ 'ya kadar olan düzelmelerin hastaların semptomlarında düzelme ile korelasyon olmadığı bulunmuştur (49-53).

MIP ve MEP sonuçlarının geçerliliği test kalitesiyle ilişkilidir. Hasta eforu ve test tekniği şüpheli sonuçlarda göz önünde bulundurulmalıdır. Test öncesi teknisyenin manevrayı bizzat göstermesi ve destekleyici test yönetimi ölçüm sonuçlarını olumlu yönde etkileyebilir. Yine çoklu manevra yapılması ve en yüksek değerin alınması etkili bir yöntemdir. Çoğu laboratuvar 1 dakika ara ile yapılan beş manevranın içinden en yüksek değeri seçmekteyse de 15 manevraya kadar yapılarak en yüksek değerin seçilmesi daha doğru sonuçlar elde edilmesi için önerilmektedir (54). Basınç ölçere bağlı olabilecek hatalı ölçümleri bertaraf edebilmek için haftada 1 kez 50 ve $100 \mathrm{cmH}_{2} \mathrm{O}$ basınçlı manometre ile cihazın doğruluk kontrolünün yapılması önerilir. Önceki ölçümler ile $5 \mathrm{cmH}_{2} \mathrm{O}^{\prime}$ dan fazla farklılık olması hata olarak kabul edilir. Genellikle sağlıklı olguların \%80-90'ı \%10'dan az değişim ile testleri yapmaktadır $(30,55)$.

Test sonuçları hasta eforu ve tekrar edilebilirliğe göre Tablo 2'de görüldüğü şekilde sınıflandırılabilir (56).

Solunum kas gücü ölçüm yöntemleri genellikle FVC, VC ve diğer SFT parametleri ile birlikte değerlendirilir. Böylece test sonuçlarını etkileyerek ve hatalı değerlendirmeye neden olabilecek faktörler dışlanabilir.

\section{KLINIK KULLANIM}

Belirgin düşük saptanan MIP, MEP ya da SNIP test çeşitli nedenlere bağlı oluşabilecek kas güçsüzlüğünü gösterir. Bu nedenlerin başlıcaları, "amyotrophic lateral sclerosis (ALS)", myastenia gravis, polymyozitis, Guillain-Barré sendromu gibi

Tablo 2. MIP ve MEP için kullanılabilecek şiddet sınıflaması

A Mükemmel (ölçümler arasında $5 \mathrm{cmH}_{2} \mathrm{O}^{\prime}$ dan daha az değişim)

B İyi (ölçümler arasında 5-10 $\mathrm{cmH}_{2} \mathrm{O}$ farklılık)

C Orta (ölçümler arasında $10-20 \mathrm{cmH}_{2} \mathrm{O}$ farklııı)

D Ölçümler içinde tek başarılı manevra

F Uygun manevra yapamayan ve tekrarlanabilirliği zayıf sonuçlar nöromusküler hastalıklar ya da kalp yetmezliği, tirotoksikoz, malnütrisyon, yoğun bakım sonrası sendromu gibi durumlar$\operatorname{dir}(35,51,52,57-60)$.

KOAH'lı hastaların çoğunluğunda hiperinflasyona bağlı olarak akciğer hacminin artışı ve dışarı doğru yer kaplamaya çalışması sonucunda inspiratuvar kasların uzunluğu azaldığı ve kas geometrisinin bozulduğu, bu nedenle maksimum inspiratuvar basınç ölçümlerinin de azaldığı 1996 yılında yapılan bir çalışmada $20 \mathrm{KOAH}$ 'lı hasta ve yedi kontrol olgusunda "maximal sniff transdiaphragmatic pressure (sniff Pdi (max)" ve "twitch transdiaphragmatic pressure (Tw Pdi)" ölçümleriyle gösterilmiştir (61).

Değerlendirmede MIP, MEP ve SNIP test solunum kas güçsüzlüğüne tanı koydurabilir. Düşük MIP ve SNIP ile normal MEP inspiratuvar kas güçsüzlüğüne ve özellikle diyafragma güçsüzlüğüne işaret ederken, MIP, SNIP ve MEP düşüklüğü genel iskelet kas güçsüzlüğüne işaret edebilir. İzole ekspiratuvar kas güçsüzlüğü (normal MIP ve SNIP ile beraber MEP düşüklüğü) nadirdir. Bu testlerdeki hafif düşüklük durumunda yaş, malnütrisyon, kötü sağlık durumu, sedanter yaşam, sigara ve suboptimal teknisyen yönetimi faktörleri gözden geçirilmelidir $(30,55)$. Gebelik MIP, MEP ve SNIP test sonuçlarını etkilemez (62).

MIP, MEP ve SNIP test doğru yapılan ve diğer etkileyebilecek faktörlerin dışlanması durumunda kas güçsüzlüğünün şiddetini ve seyrini belirleyebilirler. Normal değerlerin 1/3'ü kadar düşük olan MIP genellikle hiperkapnik solunum yetmezliği ile birliktedir $\left(\mathrm{PaCO}_{2}>45 \mathrm{mmHg}\right)$ (35). Beklenen değerin \%35'i ve altında SNIP test sonucu ALS'li hastalarda genellikle solunum yetmezliği ile birliktedir $(35,63)$. 60 $\mathrm{CmH}_{2} \mathrm{O}^{\prime}$ un altında bir MEP değeri genellikle zayıf öksürük refleksini ve sekresyonların temizliğindeki yetersizliği gösterir $(64,65)$.

Solunum kas gücü rezervinin, yetmezliği ya da zayıflığı uzun süre kompanse edebilmesi nedeniyle solunum kas gücü yetmezliği semptomları çıktığında MIP, MEP ya da SNIP test genellikle belirgin düşmüştür. Bu nedenle özellikle kronik akciğer hastalığı olan ya da kalp yetmezliği olan ve sürekli sedanter yaşayan hastalarda semptomlar çıkana kadar solunum kas güçsüzlüğü klinik olarak fark edilmeyebilir.

\section{KAYNAKLAR}

1. Hall JE. Pulmonary ventilation. In: Guyton AC, Hall JE (eds). Textbook of Medical Physiology. 13 ${ }^{\text {th }}$ ed. Philadelphia: Elsevier, 2016:497507.

2. Benditt JO, Dennis MC. The respiratory system and neuromuscular diseases. In: Mason JR, Broaddus VC, Martin TR, King TE, Schraufnagel DE, Murray JF, Nadel JA (eds). Murray and Nadel's Textbook of Respiratory Medicine. Philadelphia: Saunders \& Elsevier, 2010:1691-706.

3. Fell SC. Surgical anatomy of the diaphragm and phrenic nevre. Chest Surg Clin North Am 1998;8:281-94. [CrossRef] 
4. Braun NMT, Arora NS, Rochester DF. Force-lenght relationship of normal human diaphragm. J Appl Physiol 1982;53:405-12. [CrossRef]

5. Karakurt Z, Güngör G. Solunum kas gücü değerlendirmesi. Saryal SB, Ulubay G (editörler). Solunum Fonksiyon Testleri. İstanbul: Aves Yayınclık, 2012:95-113.

6. Gibson GJ, Pride NB, Newsom Davis J, Loh C. Pulmonary mechanics in patients with respiratory muscle weakness. Am Rev Respir Dis 1977;115:389-95. [CrossRef]

7. Estenne M, Heilporn A, Delhez L, Yernault J-C, De Troyer A. Chest wall stiffness in patients with chronic respiratory muscle weakness. Am Rev Respir Dis 1983;128:1002-7. [CrossRef]

8. De Troyer A, Borenstein S, Cordier R. Analysis of lung volume restriction in patients with respiratory muscle weakness. Thorax 1980;35:603-10. [CrossRef]

9. Estenne M, Gevenois PA, Kinnear W, Soudon P, Heilporn A, De Troyer $A$. Lung volume restriction in patients with chronic respiratory muscle weakness: the role of microatelectasis. Thorax 1993;48:698701. [CrossRef]

10. Mier A. Respiratory muscle weakness. Respir Med 1990;84:351-9. [CrossRef]

11. Jackson CE, Rosenfeld J, Moore $\mathrm{DH}$, et al. A preliminary evaluation of a prospective study of pulmonary function studies and symptoms of hypoventilation in ALS/MND patients. J Neurol Sci 2001;191:75-8. [CrossRef]

12. Mier-Jedrzejowicz A, Brophy C, Moxham J, Green M. Assessment of diaphragm weakness. Am Rev Respir Dis 1988;137:877-83. [CrossRef]

13. Allen SM, Hunt B, Green M. Fall in vital capacity with posture. Br J Dis Chest 1985;79:267-71. [CrossRef]

14. Laroche CM, Carroll N, Moxham J, Green M. Clinical significance of severe isolated diaphragm weakness. Am Rev Respir Dis 1988;138:862-6. [CrossRef]

15. Black LF, Hyatt RE. Maximal static respiratory pressures in generalised neuromuscular disease. Am Rev Respir Dis 1971;103:641-50. [CrossRef]

16. Fallat RJ, Jewitt B, Bass M, Kamm B, Norris FH. Spirometry in amyotrophic lateral sclerosis. Arch Neurol 1979;36:74-80. [CrossRef]

17. Phillips MF, Smith PE, Carroll N, Edwards RH, Calverley PM. Nocturnal oxygenation and prognosis in Duchenne muscular dystrophy. Am J Respir Crit Care Med 1999;160:198-202. [CrossRef]

18. Steier J, Kaul S, Seymour J, et al. The value of multiple tests of respiratory muscle strength. Thorax 2007;62:975-80. [CrossRef]

19. Kreitzer SM, Saunders NA, Tyler HR, Ingram RH. Respiratory muscle function in amyotrophic lateral sclerosis. Am Rev Respir Dis 1978;117:437-47. [CrossRef]

20. Vincken WG, Cosio MG. Flow oscillations on the flow-volume loop: clinical and physiological implications. Eur Respir J 1989;2:543-9. [CrossRef]

21. ATS/ERS Statement on respiratory muscle testing. Am J Respir Crit Care Med 2002;166:518-624. [CrossRef]

22. Dillard TA, Piantadosi S, Rajagopal DR. Prediction of ventilation at maximal exercise in chronic air-flow obstruction. Am Rev Respir Dis 1985;132:230-5. [CrossRef]

23. American Thoracic Society. Standardization of spirometry: 1994 update. Am J Respir Crit Care Med 1995;152:1107-36. [CrossRef]

24. Hamnegard CH, Wragg S, Kyroussis D, Aquilina R, Moxham J, Green $\mathrm{M}$. Portable measurement of maximum mouth pressures. Eur Respir J 1994;7:398-401. [CrossRef]
25. Enright PL, Kronmal RA, Manolio TA, Schenker MB, Hyatt RE. Respiratory muscle strength in the elderly. Correlates and reference values. Cardiovascular Health Study Research Group. Am J Respir Crit Care Med 1994;149:430-8. [CrossRef]

26. Wen AS, Woo MS, Keens TG. How many maneuvers are required to measure maximal inspiratory pressure accurately. Chest 1997;111:802-27. [CrossRef]

27. Kamansky DA. Spirometry and related tests. In: Ruppel GL (ed). Manual of Pulmonary Function Testing. $9^{\text {th }}$ ed. China: Elsevier, 2009:36-89.

28. Gaultier C, Zinman R. Maximal static pressures in healthy children. Respir Physiol 1983; 51:45-61. [CrossRef]

29. Leech JA, Ghezzo H, Stevens D, Becklake MR. Respiratory pressures and function in young adults. Am Rev Respir Dis 1983; 128:17-23. [CrossRef]

30. Harik-Khan RI, Wise RA, Fozard JL. Determinants of maximal inspiratory pressure: the Baltimore Longitudinal Study of Aging. Am J Respir Crit Care Med 1998;158:1459-64. [CrossRef]

31. Enright PL, Kronmal RA, Manolino TA, et al. Respiratory muscle strength in the elderly. Correlates and reference values. Am J Respir Crit Care Med 1994;149:430-8. [CrossRef]

32. Bruschi, C, Cerveri, I, Zoia, MC, et al. Reference values of maximal respiratory mouth pressures: a population-based study. Am Rev Respir Dis 1992;146:790-3. [CrossRef]

33. Héritier F, Rahm F, Pasche P, Fitting JW. Sniff nasal inspiratory pressure. A noninvasive assessment of inspiratory muscle strength. Am J Respir Crit Care Med 1994;150:1678-83. [CrossRef]

34. Uldry C, Janssens JP, de Muralt B, Fitting JW. Sniff nasal inspiratory pressure in patients with chronic obstructive pulmonary disease. Eur Respir J 1997;10:1292-6. [CrossRef]

35. Lyall RA, Donaldson N, Polkey MI, Leigh PN, Moxham J. Respiratory muscle strength and ventilatory failure in amyotrophic lateral sclerosis. Brain 2001;124:2000-13. [CrossRef]

36. Mills GH, Kyroussis D, Hamnegard CH, Wragg S, Moxham J, Green $M$. Unilateral magnetic stimulation of the phrenic nerve. Thorax 1995;50:1162-72. [CrossRef]

37. Mills GH, Kyroussis D, Hamnegard CH, Polkey MI, Green M, Moxham J. Bilateral magnetic stimulation of the phrenic nerves from an anterolateral approach. Am J Respir Crit Care Med 1996;154:1099105. [CrossRef]

38. Watson AC, Hughes PD, Louise Harris M, et al. Measurement of twitch transdiaphragmatic, esophageal, and endotracheal tube pressure with bilateral anterolateral magnetic phrenic nerve stimulation in patients in the intensive care unit. Crit Care Med 2001;29:1325-31. [CrossRef]

39. Hopkinson NS, Dayer MJ, Moxham J, Polkey MI. Abdominal muscle fatigue following exercise in chronic obstructive pulmonary disease. Respir Res 2010;11:15. [CrossRef]

40. Fitting JW, Grassino A. Diagnosis of diaphragmatic dysfunction. Clin Chest Med 1987;8:91-103. [CrossRef]

41. Onal E, Lopata M, Ginzburg AS, O'Connor TD. Diaphragmatic EMG and transdiaphragmatic pressure measurements with a single catheter. Am Rev Respir Dis 1981;124:563-5. [CrossRef]

42. Sinderby CA, Beck JC, Lindström LH, Grassino AE. Enhancement of signal quality in esophageal recordings of diaphragm EMG. J Appl Physiol (1985) 1997;82:1370-7. [CrossRef]

43. Laghi F, Harrison MJ, Tobin MJ. Comparison of magnetic and electrical phrenic nerve stimulation in assessment of diaphragmatic contractility. J Appl Physiol (1985) 1996;80:1731-42. [CrossRef] 
44. Rochester DF. Tests of respiratory muscle function. Clin Chest Med 1988;9:249-61. [CrossRef]

45. Steier J, Kaul S, Seymour J, et al. The value of multiple tests of respiratory muscle strength. Thorax 2007;62:975-80. [CrossRef]

46. Moxham J. Lung function tests: physiological principles and clinical applications. In: Hughes JB, Pride NB, Saunders WB (eds). London: Respiratory Muscles, 1999.

47. Aldrich TK, Spiro P. Maximal inspiratory pressure: does reproducibility indicate full effort? Thorax 1995;50:40. [CrossRef]

48. Celli BR. Clinical and physiologic evaluation of respiratory muscle function. Clin Chest Med 1989;10:199-214. [CrossRef]

49. Bland JM, Altman DG. Statistical methods for assessing agreement between two methods of clinical measurement. Lancet 1986;1:307. [CrossRef]

50. Maillard JO, Burdet L, van Melle G, Fitting JW. Reproducibility of twitch mouth pressure, sniff nasal inspiratory pressure, and maximal inspiratory pressure. Eur Respir J 1998;11:901-5. [CrossRef]

51. Keenan SP, Alexander D, Road JD, et al. Ventilatory muscle strength and endurance in myasthenia gravis. Eur Respir J 1995; 8:1130-5. [CrossRef]

52. Goswami R, Guleria R, Gupta AK, et al. Prevalence of diaphragmatic muscle weakness and dyspnoea in Graves' disease and their reversibility with carbimazole therapy. Eur J Endocrinol 2002;147:299-303. [CrossRef]

53. Nava S, Crotti P, Gurrieri G, et al. Effect of a beta 2-agonist (broxaterol) on respiratory muscle strength and endurance in patients with COPD with irreversible airway obstruction. Chest 1992;101:133. [CrossRef]

54. Larson JL, Covey MK, Vitalo CA, et al. Maximal inspiratory pressure. Learning effect and test-retest reliability in patients with chronic obstructive pulmonary disease. Chest 1993;104:448. [CrossRef]

55. Carpenter MA, Tockman MS, Hutchinson RG, et al. Demographic and anthropometric correlates of maximum inspiratory pressure: The Atherosclerosis Risk in Communities Study. Am J Respir Crit Care Med 1999;159:415-22. [CrossRef]
56. http://www.uptodate.com/contents/tests-of-respiratory-muscle-strength [CrossRef]

57. Lechtzin N, Wiener CM, Shade DM, et al. Spirometry in the supine position improves the detection of diaphragmatic weakness in patients with amyotrophic lateral sclerosis. Chest 2002;121:436-42. [CrossRef]

58. Polkey MI, Lyall RA, Green M, et al. Expiratory muscle function in amyotrophic lateral sclerosis. Am J Respir Crit Care Med 1998;158:734-41. [CrossRef]

59. Teixeira A, Cherin P, Demoule A, et al. Diaphragmatic dysfunction in patients with idiopathic inflammatory myopathies. Neuromuscul Disord 2005;15:32-9. [CrossRef]

60. Hughes PD, Polkey MI, Harrus ML, et al. Diaphragm strength in chronic heart failure. Am J Respir Crit Care Med 1999;160:529-34. [CrossRef]

61. Polkey MI, Kyroussis D, Hamnegard $\mathrm{CH}$, et al. Diaphragm strength in chronic obstructive pulmonary disease. Am J Respir Crit Care Med 1996;154:1310. [CrossRef]

62. Lemos A, de Souza Al, Figueiroa JN, et al. Respiratory muscle strength in pregnancy. Respir Med 2010;104:1638-44. [CrossRef]

63. Morgan RK, McNally S, Alexander M, et al. Use of Sniff nasal-inspiratory force to predict survival in amyotrophic lateral sclerosis. Am J Respir Crit Care Med 2005;171:269-74. [CrossRef]

64. Man WD, Kyroussis D, Fleming TA, et al. Cough gastric pressure and maximum expiratory mouth pressure in humans. Am J Respir Crit Care Med 2003;168:714-7. [CrossRef]

65. Szeinberg A, Tabachnik E, Rashed N, et al. Cough capacity in patients with muscular dystrophy. Chest 1988;94:1232-5. [CrossRef] 